\title{
A study on the influence of big data on the user experience of Electronic Commerce
}

\author{
Qiulian Sun \\ Jiangxi Vocational Techical College Of Industry \& Trade, Jiangxi, Nanchang,330038
}

key words Big data; e-commerce; user experience; impact

\begin{abstract}
In the environment of rapid development of modern information technology, the development of e-commerce has been a broader opportunity because of the existence of big data. With today's technology, big data can be summarized and analyzed, and the key information can be collected. E-commerce sites can use these key information to help make decisions and optimize the user purchase experience. This paper mainly analyzes the relationship between big data and electronic commerce from the use of big data, and analyzes the relationship between big data and electronic commerce, as well as the significance of big data development.
\end{abstract}

\section{The Development Trend of the Big Data Age}

Big data is the inevitable result of the development of information technology in line with the development trend of the times. Now online sales staff using big data's way may make people feel scary and difficult to accept. When a user searches the Internet for a keyword, the user receives only ads related to the keyword throughout the week after browsing any site. This phenomenon is the result of making full use of big data's technology. But don't think it's a sinister attempt to collect information about Internet users. These network data not only come from my network use, but also from other network users. Ecommerce will take these The scattered data is collected and sorted, and the behavior of the designated user population is predicted according to the result of the data analysis. In this data collection process, the user's real name is hidden and does not exist for a given user. When big data is used in e-commerce, users can find goods and content that meet their needs more quickly and conveniently.

\section{Big Data Customization User Experience}

For users with a desire for shopping, big-data applications are no doubt very helpful, but for users who don't want to go shopping, pushing ads are like harassing messages and making people feel uncomfortable. But for e-commerce, it is vital to understand the customer's needs and consumption habits, and the application of big data will undoubtedly bring great benefits to the business. In general, when a customer seeks a commodity or service, the traditional search results can have a large amount of value-free information, and the time required is long, but if a personalized presentation search result is carried out for the user, the time for the user to find the heart instrument product will be greatly shortened. pair For businesses, they need to sell more goods, for consumers, they need to save more time looking for goods. Big data's application has brought win-win results to both. The personalized search results displayed by ecommerce are not $100 \%$ clicked by users, and it is difficult to infer the real results without sufficient effective information data. Therefore, it is necessary to optimize and upgrade the algorithm in order to complete the analysis of large-scale data in order to improve the accuracy of search results. Wasting time on a wide variety of websites looking for the desired goods is always a nuisance. After using big data, it is shortened from the previous hour. In a few minutes, why not. Amazon Shopping is one of the most successful e-commerce sites today. Its technology is very leading, its product recommendation function is particularly praised, after years of use accumulated a good user evaluation. To put it simply, big data provides the possibility for customized user experience and brings great convenience to shopping. 


\section{Big data can help evaluate the product}

Whether it's Amazon or any other e-commerce platform, it's a common phenomenon to ask users for a shopping experience. The way the user feeds back to e-commerce is to express the purchase experience by scoring. Not only is it a simple score, but the user will typically leave a fairly detailed product-use experience, leaving a number of important information to provide a reference for potential buyers in the back if they have the value of the purchase. This is only one of the forms of big data applications. The more the evaluation of a commodity is collected, the more the real value of the product is to be displayed, and if there is no big data to do so, Processing and filtering worthless information, then users will be difficult to choose among the fish mixed beads of goods, easy to produce a poor shopping experience.

\section{Big data makes it more economical for users to buy}

Online shopping is becoming more and more important, compared with the traditional shopping method, it can save time and cost more. No matter what kind of commodity, it can achieve lower price trading on the Internet. Although online shopping has many advantages, but it also has a very obvious drawback, that is, after the purchase of goods, can not get the goods immediately. Now the development of the logistics industry has greatly improved this drawback. In the past, users also wanted to buy goods online. Shopping on the Internet may naturally be the case, but users do not have so much time and energy to choose and compare one by one on complicated websites, but big data can help users to complete the selection. The task of selecting the most cost-effective goods. Some of the specific operations of big data to achieve this work are: using a unique program to retrieve the applicable coupons and provide the coupon code to the user. As if to become a necessity in people's daily life, is a part of life, today, we can receive our favorite items at home, but also can choose, and then through many comparisons, to buy the products we need at a low price. The emergence of this model also makes the bargaining behavior disappear, so the behavior of being deceived is greatly reduced. Not limited to this, consumers. Perhaps there are more special preferences, so customized products to better meet the needs of consumers.

\section{Big data can provide users with more valuable information}

There is a mutually beneficial relationship between the user and the e-commerce. The data and information generated by the user are collected and utilized by the e-commerce, and the e-commerce website analyzes the data to continuously improve the user experience. The more information is exchanged between the two, the more perfect the user's shopping experience, and the e-commerce web site will gain more. This advantage is an important reason for the online shopping mode to gradually challenge the traditional shopping mode off-line. the e-commerce platform can predict the consumption behavior of the user by collecting the data of the user, understand the user's demand, screen the non-value information, display more valuable information for the user, Complete the service to provide a better shopping experience for the user. E-commerce has made an in-depth study on the consumer's consumer concept, in order to attract more customers, so that the product can get more marketing. So, the first thing to be guaranteed is that there are more innovative thinking and ways, so that the marketing system gets more development, so that the consumer can get a better and satisfactory consumption experience, and can also have more choices and requirements. The purpose of the creation of Taobao is to improve people's living standards so as to meet the needs and development potential of people. The full range of the goods is its great advantage, no matter what high-end you need The product, or affordable products, you can gain, at the same time, a lot of virtual transactions, can also give you a rich experience, such as charging and vip, and so on. Whether you are online or offline personnel, can experience its great advantages, cannot be ignored, after-sales problems also really need to ensure that only in this way to bring consumers more security, consumers can negotiate with merchants, if there is a quality problem, merchants can provide return or replacement, strive to better serve consumers. 


\section{Big data can better meet the concept of customer consumption}

Under the influence of big data, the consumer is the necessary premise of the existence of e-commerce, the existence of the customer is its value, and the long-term view needs to be put into the consumer. Big data e-commerce has a deep influence, through big data, can analyze the consumption situation suitable for the public. In production and consumption, there is a pivot function. In the case of a single user, through the analysis of large data, it is possible to know the characteristics of the shopping. The consumer is the meaning of the enterprise, and want more to know the customer's needs, it can be analyzed through a lot of data, so it can be beneficial to the consumer to know well The survival of the enterprise lies in the development. At present, the service level of enterprises is not optimistic and is at a lower level. Using big data for systematic analysis can make its services more effective, and the most important way is to sell products to consumers. E-commerce, in these years has also been the corresponding development, the model is also gradually improved, big data contributed to this.

\section{Conclusion:}

It provides very useful information for e-commerce platform and consumer users by completing the processing and analysis of the data. Both of which have obtained more convenience. The customized search result provided by the e-commerce website to the consumption user is shown, the consumption requirement of the user is better met, and the time and energy and the cost of the consumption user are saved. And the information fed back by the user to the e-commerce website. The e-commerce website is supported to improve the quality of service and to achieve more benefits. In short, big data technology will have a deep and favorable impact on the development of e-commerce.

\section{References:}

[1] Analysis on the Application of big data Technology in Electronic Commerce platform and Enterprises[J]. Fan Jinghong. Science and technology wind. 2019(11)

[2] Analysis of Electronic Commerce Security and data Analysis platform in big data era[J]. Liaojuan,Ruan Yunfei . Computer knowledge and technology. 2019(10)

[3] The Application of Big Data Technology in E-commerce[J]. Zhanghong. Electronic Technology and Software Engineering . 2019(09)

[4] Management Mode of Electronic Commerce Enterprises from the Perspective of big data[J]. Panluo. National circulation economy . 2019(09)

[5] Research on the Security of computer Electronic Commerce in big data's era[J]. Wanghua. Message communication. 2019(09)

[6] The User's Advantages of Big Data and Internet of Things in E-commerce[J]. Liuyue. The Economic Development of the Bohai Sea. 2019(09)

[7] Research on Electronic Commerce Industry from big data's Perspective[J]. Gao haijian. Capital University of Economics and Trade. 2015(03) 